is eventually prevented duc to an interruption of cellular proliferations, which is caused by a strong reduction in DNA contents of granulomatous tissuc in rats treated with hydroxyurea.

\title{
REFERENCES
}

1) Suin, K.H., Nakaciawa, H. anis Tsurupuir, S.: Biochem. Pharmacol, 23, 381 (1974); 2) Rosfnkranz, H.S. AND LiYY, J.A.: Biochem. biophys. Acta 95, 181 (1965); 3) Young, C.W. and Hodas, S.: Science 146, 1172 (1964); 4) Yarbio, J.W., Niwhaus, W.G. and Barnum, C.P.: Biochem. hiophys. Res. Commum. 19, (5) 592 (1965); 5) Fukuhara, M. and Tsurufusi, S.: Biochem. Pharmacol. 18, 475 (1969); 6) Degriengi, R.: Org. Synth. 40, 60 (1960); 7) Nakagawa, H. and Tsurufujl, S.: Biochem. Pharmacol. 20, 2253 (1971)

\section{INHIBITIONS BY COLCHICINE, VINBLASTINE AND CYTO- CHALASIN-B OF THF STIMULATORY EFFECT OF THE CYTOPLASMIC FRACTION ON CATECHOLAMINE RELEASE FROM ADRENOMEDULLARY GRANULES}

\author{
Motoo OKA. Takeshi KASHIMOTO and Futoshi IZLMI \\ Department of Pharmacology H, Osaka University School of Medicine, Osaha. Japan \\ Accepted October 11, 1974
}

Microtubules and microfilaments have been regarded as being involved in release of hormones and amines, since agents, such as colchicine and vinblastine, and cytochalisin-B. which disrupt microtubules and microfilaments, respectively, inhibit the release of hormones or amines from cells (1-11). Stimulation of the release of catecholamine from perfused adrenal gland by acetylcholine or nicotine is also inhibited by colchicine, vinblastine or cytochalasin-B (12-15).

In our previous studies on the intracellular mechanism of catecholamine release, using isolated adrenal medullary granules, it was demonstrated that the release of catecholamine is stimulated by ATP. $\mathrm{Mg}^{++}$in the presence of a low concentration of $\mathrm{Ca}^{++}\left(<10^{-5}\right.$ M) $(16,17)$ and that a cytoplasmic fraction of adrenal medulla (supernatant obtained by centrifugation at $105,000 \therefore \mathrm{g}$ for $2 \mathrm{hr}$ ) accelerales $\mathrm{ATP} \cdot \mathrm{Mg}^{++}$stimulated catecholamine release from the granules (18).

In the present work, the effects of colchicine, vinblastine and cytochalasin-B on the stimulatory effect of the cytoplasmic fraction on catecholamine release were examined, to determine whether microtubules and microfilaments-like components are involved in the stimulatory effect of the cyloplasmic fraction. Catecholamine storage granules and the cytoplasmic fraction from hovine adrenal medulla were prepared as described previously (18). Incubations were carried out as described in the footnote of Fig. 1.

Results are summarized in Iig. 1. During the incubation period, $18.2 \cdot 3.6^{\circ}$ (mean - 


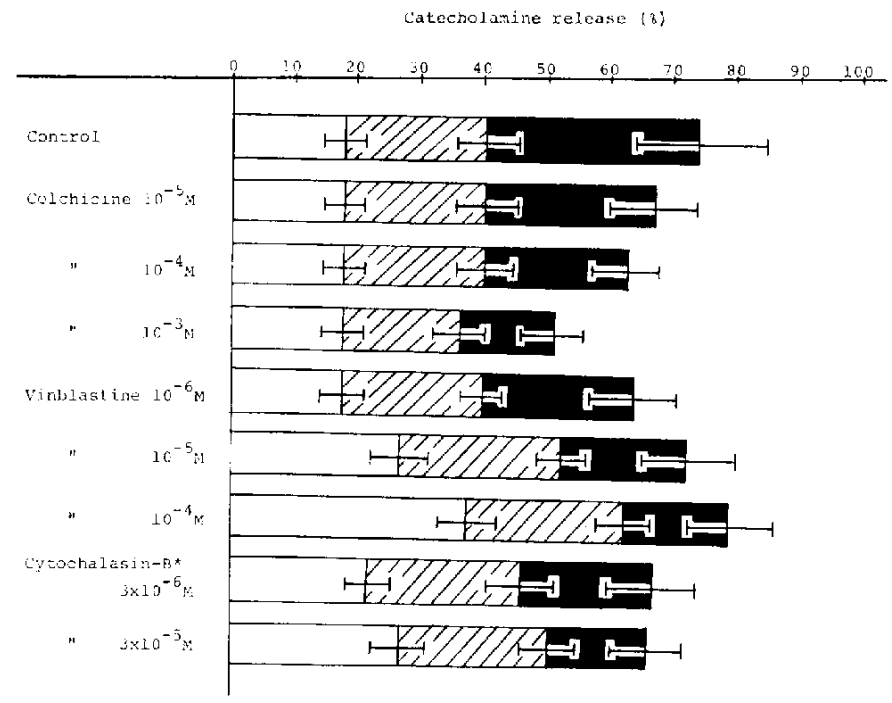

Frg. 1. Effects of colchicine, vinblastine and cytochalasin-B on the release of catecholamine from adrenal medullary granules.

Incubations were carried out at $37^{\circ} \mathrm{C}$ for $5 \mathrm{~min}$ in centrifuge tubes without shaking. The medium contained $150 \mathrm{mM} \mathrm{KCl}$ and $10 \mathrm{mM}$ Tris-Maleate buffer (pH 7.0) with or without $2 \mathrm{mM} \mathrm{ATP}-1 \mathrm{mM} \mathrm{MgCl} 2$ and the cytoplasmic fraction $(1.5 \mathrm{mg} / \mathrm{ml})$ in a final volume of $3 \mathrm{ml}$. After pre-incubation for $5 \mathrm{~min}$, the reaction was started by adding the granules (about $2 \mathrm{mg}$ of protein, containing $400-500 \mu \mathrm{g}$ of catecholamine). The reaction was stopped by adding $4 \mathrm{ml}$ of ice cold $150 \mathrm{mM} \mathrm{KCl}$ containing $10 \mathrm{mM}$ Tris-Maleate buffer (pH 7.0). The tubes were then chilled in ice and centrifuged at $20,000 \times \mathrm{g}$ for $10 \mathrm{~min}$. Catecholamine in the precipitate and supernatant was extracted with $0.4 \mathrm{~N}$ perchloric acid and determined fluorimetrically by the ethylenediamine condensation method (19).

Columns, and bars represent means $上$ S.D. of the releases in 4 to 12 experiments, expressed as percentages of the total catecholamine.

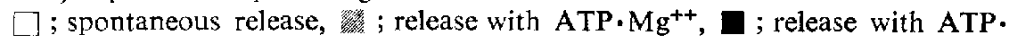
$\mathrm{Mg}^{++}$and the cytoplasmic fraction. * Cytochalasin-B was dissolved in $0.25 \%$ $(\mathbf{v} / \mathbf{v})$ dimethylsulfoxide

S.D.; $n=12$ ) of the total catecholamine was released spontaneously from the granules. Release of catecholamine increased to $40.5=5.8 \%$ (mean \pm S.D.; $n=12)$ on addition of ATP and $\mathrm{Mg}^{++}$, and to $73.7 \mid 11.2 \%$ (mean \pm S.D.; $\mathrm{n}-12$ ) on addition of the cytoplasmic fraction with ATP and $\mathrm{Mg}^{++}$, thus confirming previous results (18). Addition of the cytoplasmic fraction in the absence of ATP and $\mathrm{Mg}^{++}$did not increase the release of catecholamine.

Colchicine at concentrations of $10^{-4} \mathrm{M}$ and $10^{-3} \mathrm{M}$ was found to inhibit the stimulatory effect of the cytoplasmic fraction on catecholamine release by $30 \%$ and $56 \%$, respectively. A low concentration of colchicine $\left(10^{-5} \mathrm{M}\right)$ was only partially inhibitory. Colchicine at a concentration of $10^{-3} \mathrm{M}$ had no effect on the spontaneous release of catecholamine, but slightly inhibiled ATP. $\mathrm{Mg}^{++}$stimulated catecholamine release. Colchicine was more inhibitory when pre-incubated with the cytoplasmic fraction, that is when the cytoplasmic fraction was pre-incubated with $10^{-4} \mathrm{M}$ colchicine for $2 \mathrm{hr}, 50 \%$ inhibition was observed (results not shown). 
Vinblastine was also found to inhibit the stimulatory effect of the cytoplasmic fraction on catecholamine release. It was inhibitory at lower concentrations than colchicine, and concentrations of $10^{-6} \mathrm{M}, 10^{-5} \mathrm{M}$ and $10^{-4} \mathrm{M}$ caused $30 \%, 40 \%$ and $52 \%$ inhibition of the effect of the cytoplasmic fraction, respectively. Concentrations of more than $10^{-5} \mathrm{M}$ significantly increased th spontaneous release of catecholamine, but had little effect on ATP. $\mathrm{Mg}^{++}$stimulated catecholamine release.

Cytochalasin-B also inhibited the stimulatory effect of the cytoplasmic fraction. It was effective at concentrations similar to those used for vinblastine, and concentrations of $3 \times 10^{-6} \mathrm{M}$ and $3 \times 10^{-5} \mathrm{M}$ inhibited the effect of the cytoplasmic fraction by $34 \%$ and $52 \%$ respectively. Spontaneous release appeared to be stimulated much to the same degree by $3 \times 10^{-5} \mathrm{M}$ cytochalasin- $\mathrm{B}$ and $10^{-5} \mathrm{M}$ vinblastine.

From the above results, it is suggested that the cytoplasmic fraction contains elements which are affected by colchicine, vinblastine and cytochalasin-B and that these elements (possibly microtubules and microfilaments-like elements) may be involved in the stimulatory effect of the cytoplasmic fraction on the release of catecholamines from adrenomedullary granules.

\section{REFERENCES}

1) LACY, P.E., Howlld, S.L., Young, D.A. AND Fink, C.: Nature 219, 117 (1968); 2) MAlaisse-Lagae, F., Greider, M.H., Malaisse, W.J., Lacy, P.E.: J. cell Biol. 49, 530 (1971); 3) Gillespie, E., Levine, R.J., Malawista, S.E.: J. Pharmacol. exp. Ther. 164, 158 (1968); 4) Llyr, D.A. and Carlton, J.A.: Proc. Soc. exp. Biol. 130, 1333 (1969); 5) Orr, T.S.C., Hall, D.E. And Allison, A.C.: Nature 236, 350 (1972); 6) Kraicer, J. and Millician, J.V.: Endocrinology 89, 408 (1971); 7) SHOFIELd, J.G.: Nature 234, 215 (1971); 8) BUTCHER, F.R. AND Goldmax, R.H.: Biochem. biophys. Res. Commun. 48, 23 (1972); 9) Williams, H.A. AND Wol.fF, J.: Proc. Natn. Acad. Sci. 67, 1901 (1970); 10) ThoA, N.B., Wooten, G.F., Axtlrod, J. And Kopin, I.J.: Proc. Natn. Acad. Sci. 69, 520 (1972); 11) Sorimachi, M., Oesch, F. and Thoenen, H.: Arch. Pharmacol. 276, 1 (1973); 12) Poisner, A.M. and BernstFin, J.: J. Pharmacol exp. Ther. 177, 102 (1971); 13) Douglas, W.W. And Sorimachl, M.: Brit. J. Pharmacol. 45, 143p (1972); 14) DoUglas, W.W. AND SORIMACHI, M.: Brit. J. Pharmacol. 45, 129 (1972); 15) Trifaro, J.M. Collier, B., Lastowecka, A. and Stern, D.: Mol. Pharmacol. 8, 264 (1972); 16) OKa, M., Izumi, F. and Kashimoto, T.: Japan. J. Pharmacol. 21, $680(1971)$; 17) IZUMi, F., OKA, M. AND Kasilimoto, T.: Japan. J. Pharmacol. 21. 739 (1971); 18) Oka, M., IZumi, F. and Kashimoto, T.: Japan. J. Pharmacol. 22, 207 (1972); 19) Weli-Malherbi, H. ANd Bone, A.D.: Biochem. J. 51, 311 (1952) 